\title{
Time Perspective and the Risk of Developing Burnout: An Empirical Study among Different Blue-Collar Workers in Spain
}

\author{
Adela Reig-Botella ${ }^{1,2, *(\mathbb{D})}$, Sarah Detaille ${ }^{1,2}$, Miguel Clemente ${ }^{2}{ }^{(\mathbb{C}}$, Jaime López-Golpe ${ }^{2}$ and Annet de Lange ${ }^{1,2,3,4,5}$ \\ 1 Department of Human Resource Management, HAN University of Applied Sciences in Nijmegen, \\ 6525EJ Nijmegen, The Netherlands; sarah.detaille@han.nl (S.D.); annet.delange@han.nl (A.d.L.) \\ 2 Department of Psychology, Universidade da Coruna, 15701 A Coruna, Spain; miguel.clemente@udc.es (M.C.); \\ jaime.lopez.golpe@gmail.com (J.L.-G.) \\ 3 Faculty of Psychology, Open University Heerlen, 6419AT Heerlen, The Netherlands \\ 4 Faculty of Social Sciences, University of Stavanger, 4021 Stavanger, Norway \\ 5 Faculty of Psychology, Norwegian University of Science and Technology (NTNU), 7491 Trondheim, Norway \\ * Correspondence: adela.reig@udc.es
}

Citation: Reig-Botella, A.; Detaille, S.; Clemente, M.; López-Golpe, J.; de Lange, A. Time Perspective and the Risk of Developing Burnout: An Empirical Study among Different Blue-Collar Workers in Spain. Sustainability 2021, 13, 3271. https:// doi.org/10.3390/su13063271

Received: 11 February 2021

Accepted: 9 March 2021

Published: 16 March 2021

Publisher's Note: MDPI stays neutral with regard to jurisdictional claims in published maps and institutional affiliations.

Copyright: (c) 2021 by the authors. Licensee MDPI, Basel, Switzerland. This article is an open access article distributed under the terms and conditions of the Creative Commons Attribution (CC BY) license (https:// creativecommons.org/licenses/by/ $4.0 /)$.

\begin{abstract}
The purpose of this research was to analyze the relationship between the time perspective of Spanish shipyard workers in relation to burnout compared to other blue-collar workers in other sectors, including a total of 644 participants in a shipyard in northern Spain and 223 workers in other sectors. The ages were between 20 and $69(\mathrm{M}=46.14$, SD = 10.98). We used the Spanish version of the Zimbardo Time Perspective Instrument (ZTPI) and the Maslach Burnout Inventory-General Survey (MBI-GS). The mean of the three reliability coefficients of the emotional exhaustion factor was 0.887. In respect to the five factors of the ZTPI questionnaire, the mean of those five coefficients was 0.86. A Student's $t$-test for independent samples comparing shipyard naval workers vs. the control group in personality variables and burnout was used. The psychological difference between workers in the naval sector and those in other sectors is better predicted based on two variables: emotional exhaustion and professional efficacy. Workers in the naval sector have a higher risk of becoming burnt-out than workers in other sectors due to a negative past, present and future time perspective. This can be a consequence of constant understimulation and monotonous and repetitive work, as well as a lack of autonomy and social support at work.
\end{abstract}

Keywords: blue-collar workers; burnout; cross-sectional; occupational health; sectors; shipyard; time perspective

\section{Introduction}

The aim of this paper concerns the relationship between time perspective in relation to the risk of developing burnout in workers of different sectors and different types of demanding work (predominantly different types of low-skilled work and/or blue-collar work) in Spain. Up to now, there has been little awareness of the concept of time perspective in relation to the mental health of workers in different sectors in the field of occupational health. Despite this, prior research has indicated the value of studying time perspective because it significantly influences an individual's judgments, decisions and actions [1,2]. Labor conditions within different work environments can have a serious effect on the mental health of workers.

The working conditions at shipyards are harsh due to predominantly heavy manual and repetitive work, as well as difficult environmental working factors such as air and noise pollution [3,4], which may lead to mental health issues. Moreover, we find in the literature that burnout is also likely to occur when interpersonal resources (e.g., social support from colleagues and supervisors) or other resources (e.g., feedback, participation in decision making and job control) that are instrumental in achieving one's work goals are lacking $[5,6]$. Other studies have found that carrying out monotonous and short-cycle 
repetitive work tasks, as are often found in, for instance, mechanical assembly, inspection and monitoring jobs, is associated with boredom, and boredom at work is related to mental underload, (e.g., mindless jobs) when employee abilities exceed their task demands (i.e., skill underutilization) $[7,8]$. These issues make investigating the influence of time perspective among different types of workers in relation to the possible development of burnout interesting. Before we address the specific research questions and hypotheses of the current study, we will focus on the concept and related theory of burnout as well as time perspective.

Burnout is a condition of psychological and physica fatigue. Maslach and Jackson [9] divided this condition into three elements: Fatigue refers to a feeling of severe long-term exhaustion and the absence of eagerness and energy toward work, which is induced by experiencing a sustained and challenging work environment [10]. Cynicism and detachment (depersonalization) refer to a conscious effort to distance oneself from work and the manifestation of submissive, apathetic and distrustful views of and feelings towards coworkers. Personal achievement is displayed in poor self-esteem and unproductiveness in the workplace [11], as well as the incapacity to feel gratification, fulfillment and a sense of achievement linked to job performance [12]. The established practice has been to treat burnout by observing economic and social factors, without having regard for characteristics of the individuals themselves [13]. The heightening of burnout risk is a common issue in companies and institutions [14] caused by personal factors and circumstances; for example, increased workload, constant deadlines, qualitative pressures [15], lack of influence or reward [16], disputes in the workplace such a noise interference, which can also lead to high blood pressure and the burnout of blue-collar employees [17], and the absence of rewards of acknowledgment [18] is a common issue in companies and institutions [14,18,19]. Burnout is connected to the worker's capacity to control their feelings, and this ability will decide how staff members deal with particular circumstances [13]. Furthermore, it is related to greater job stress [20] and emotional fatigue [21], the latter being an important forecaster of physical ailments such as headaches, exhaustion, gastrointestinal ailments and respiratory issues, while mental effects include: insomnia, symptoms of depression, the use of psychotropic drugs and antidepressants, mental health symptoms [22], the worker's feelings of disillusionment, helplessness, irritability and feeling of fatigue [10].

Recent psychological research focuses on the reasons for and results of overstimulation in the workplace, including burnout, whereas the issue of understimulation (boredom) has not generally been recognized. The consequences of overstimulation (burnout) and understimulation (boredom) seem to partially coincide as both are distinguished by feeling fatigue [5]. Staff who feel predominantly negative emotions have an elevated risk of becoming burnt-out, while those who feel predominantly positive emotions can feel satisfied or engaged [5].

Not all workers may have the ability or possibility to put into action self-management skills at the workplace. Research has also shown that other elements may influence the risk of developing burnout: long-term experience, role, job sector satisfaction and job fulfillment [23]. Job burnout may lead to detachment from other people, a negative effect on the individual and a negative effect on the institution [24]. In the most recent International Classification of Diseases (ICD-11) [25], burnout is cited as a type of work-related stress that is not adequately controlled and is related to higher levels of job stress [20]. It is a public health issue with negative ramifications that should be avoided in the workplace [26].

The concept of time perspective may be sourced to the ground-breaking research of Kurt Lewin (1951), who contended that a person's life space incorporates both the past and future as influences on present actions and reactions, which must be assessed to comprehend a person's psychological situation [27]. Time perspective is held to be a temperamental-circumstantial model that regards the arrangement of experience into time periods: the present, the past and the future [1]. It identifies five aspects, two for each time period, and one for the future. Past positive: recollecting sentimental, comforting, favorable and sympathetic impressions of the past; Past negative: recollecting an unfavorable and an- 
tipathetic impression of the past; Future: a propensity to consider the future, optimistically planning, creating objectives to be accomplished and outcomes to be strived for; Present hedonism: enjoyment as life's goal is frequently emphasized, despite the risks implied; Present fatalism: reveals a pessimistic and cynical standpoint toward the present, considering that current endeavors by an individual are ineffectual and therefore detachment from target-focused objectives $[4,28,29]$. People are usually biased toward either the past, present or future, and this inclination has several psychological ramifications [30]. The three time periods perform a pivotal function in the interconnection between personal and communal experiences [1,31].

Research has identified multiple connections between personal characteristics and time perspectives. Personality is assessed as a relevant psychological variable related to emotional, motivational and social traits of human interactions [29,30], as well as to the requirements for positive and negative outcomes, mental health outcomes and personal fulfillment [32]; for instance, well-being, habits linked to good health [28], circadian rhythm [33], proneness to addiction, positivity, high self-confidence, unsafe driving [29-34] diligence, neuroticism, sociability and openness to new experiences and amiability [30-35]. Some experiences and consequences are derived from leisure; moreover, having or lacking spare time is related to different attitudes to life, and time perspective has an effect on most features of human conduct [36]. In organizations, the five time perspective scales are vital in understanding constructive human behavior. The future time perspective is of great importance in explaining self-management in the workplace, such as planning, decision making and motivation [37]. It is also connected to engagement in tasks, job satisfaction, organizational commitment and the intention to continue in a role, all in a positive way $[38,39]$. All these attitudes are important because they are associated with productivity, health and staff retention in an institution [40].

Temporary contracts also have an important psychological effect on staff doing work experience as well as emotional reactions at work. A sequence of temporary contracts promotes the comparison of current working conditions with those of previous employments and affects current job satisfaction $[37,40,41]$

The objective of this research was to verify whether the fact of being a worker in a naval company implies the possession of personality variables different from those of workers in other sectors and if the fact of working in the naval sector implies being more or less burnt-out on the job than when working in other sectors. The fact that in Spain there has been a continuous restructuring of the naval sector for many years implies early retirements, the existence of ever-lower workloads and the increasingly low social consideration of their profession, as it is increasingly unstable. Their situation is what motivates this article.

We formulated the following hypotheses:

General hypothesis: Shipyard workers have a more negative past, present and negative future time perspective compared to workers of other sectors due to the specific nature of this work. Furthermore, workers in the naval sector, due to the specific nature of their work, will have a higher risk of developing burnout.

In addition, three specific hypotheses were created:

Hypothesis 1 (H1). Workers in the naval sector will obtain a higher negative past, negative present and negative future time perspective than workers of other blue-collar sectors.

Hypothesis 2 (H2). Workers in the naval sector will obtain lower scores in the temporal dimension of personality (Zimbardo model) of the hedonistic present, future and positive past than workers in other blue-collar sectors.

Hypothesis 3 (H3). Workers in the naval sector will obtain higher scores on the burnout scales of emotional exhaustion and cynicism when compared with the sample of workers from other blue-collar sectors and are also lower in professional efficiency. 


\section{Materials and Methods}

\subsection{Participants}

The study group (incidental sample) consisted of 644 people: 421 workers in a shipyard in the north of Spain and 223 in other blue-collar or low-skilled sectors. Regarding the control subsample, it was very varied, including workers from sectors such as hotel, textile, construction, iron and steel, public administration, automotive sectors, etc.

The respondents were selected at random. They were given the questionnaire in person and an informed consent form. The questionnaire was applied once and completed in the organization or at home; in the latter, they were asked to deliver the questionnaire within a few days. Initially, 700 workers were contacted, of whom only 644 workers responded. This means that 56 did not reply, of whom 40 belonged to the group of workers in the naval sector and 16 to other sectors. It was considered that the two subsamples were large enough, and therefore it was not necessary to replace the subjects that did not reply, especially due to the difficulty that the process would have entailed.

Of the participants, 457 were men ( $71 \%)$, and 187 were women $(29 \%)$. The mean age was 46.14 years old $(S D=10.98)$, with a minimum of 20 and a maximum of 69 . Their predominant level of education was secondary ( 324 subjects, $50.3 \%$ ), followed by university studies (223 subjects, $34.6 \%$ ), and finally, by primary studies (94 subjects, $14.6 \%$ ). Regarding their employment situation, $74.8 \%$ had a permanent contract.

\subsection{Instruments}

\subsubsection{Zimbardo Time Perspective}

The Zimbardo Time Perspective Instrument (ZTPI) [1], the validation of the Spanish version carried out by Morales [42], consists of 56 items and was used to measure five scales: Past Positive, which reflects a warm, sentimental attitude toward the past (9 items, e.g., "Happy memories of good times spring readily to mind"); Past Negative, which reflects a generally negative, aversive view of the past (10 items, e.g., "It's hard for me to forget unpleasant images from my youth"); Present Hedonistic, which reflects a hedonistic, enjoyment and pleasure-centered risk-taking attitude toward time and life (15 items, e.g., "It is important to put excitement in my life"); Present Fatalistic, which measures a helpless and hopeless attitude toward the future and life and a sense that the future is predestined and not influenced by present individual actions (9 items, e.g., "Since whatever will be will be, it doesn't really matter what I do"); and Future, which reflects a general orientation toward the achievement of future goals and is characterized by planning and organization (13 items, e.g., "When I want to achieve something, I set goals and consider specific means for reaching those goals"). Respondents rate their degree of endorsement of each statement on a five-point Likert-type response scale $(1=$ strongly disagree to $5=$ strongly agree $)$.

The internal consistency of the ZTPI questionnaire was calculated for this research using Cronbach's Alpha index. The mean of the five coefficients was 0.87 . The first factor, negative past, obtained a coefficient of 0.93 ; the second, positive past, 0.80 ; the present, hedonistic, 0.91 ; the future, 0.81 ; and the fatalistic present, 0.93 . Therefore, the reliability of the questionnaire, already verified by their corresponding authors, is adequate.

\subsubsection{Burnout}

We used the Maslach Burnout Inventory-General Survey (MBI-GS), developed by Maslach et al. It is a 15-item self-reporting measure of job burnout that includes three dimensions, namely emotional exhaustion, depersonalization and reduced personal accomplishment [43]. The items are rated from 0 (never) to 6 (every day). Sample items are "I feel burned out from my work," "I have become less enthusiastic about my work" and "I feel confident that I am effective at getting things done."

The internal consistency of the MBI-GS questionnaire used was calculated for this research using Cronbach's Alpha index. The mean of the three reliability coefficients was 0.9. The first factor, emotional exhaustion, obtained a coefficient of 0.901; the second, 
cynicism factor, 0.902 ; and the professional efficacy factor, 0.866 . Therefore, the reliability of the questionnaire, already verified by their corresponding authors, is adequate.

\subsubsection{Data Analysis}

For the data analysis, the IBM SPSS Program version 26 was used (IBM, Armonk, NY, USA). Descriptive tests were requested in order to verify that the imported data were error free. Next, the percentages of each category were specified with reference to qualitative variables, as well as the statistics of central tendency in the case of quantitative variables. The alpha reliability index was calculated using Pearson correlations both for the items on the Zimbardo ZTPI scale and for each of the subscales. A MANOVA was carried out to compare the possible differences in the five personality variables of the Zimbardo time dimension test and in three of the tests of being burnt-out, based on being a worker in the naval sector or other sectors. Lastly, a binary logistic regression was performed, where the criterion variable was being a worker in the naval sector versus being from other sectors, and the predictor variables were five for personality and three for burnout.

\section{Results}

Firstly, the reliability of the questionnaires used was calculated using Cronbach's Alpha index. Regarding the MBI-GS questionnaire, the emotional exhaustion factor obtained a coefficient of 0.961 , the cynicism factor of 0.828 and the professional efficacy factor of 0.836 . Therefore, the mean of the three reliability coefficients was 0.875 .

With respect to the five factors of the ZTPI questionnaire, the negative past factor obtained a coefficient of 0.832 , the positive past of 0.844 , that of the present hedonist of 0.858; positive future of 0.855 and the fatalistic present of 0.891 . The mean of the five coefficients, therefore, was 0.856 , and the reliability of the two questionnaires is adequate.

Then, the descriptive values of each dependent variable (mean and standard deviation), as well as the correlations between all the variables (Table 1), were calculated. It is indicated in Table 1 which correlations are significant. This table allows discerning the relationship between the variables in the study.

Table 1. Mean, standard deviation and correlations of all the variables.

\begin{tabular}{|c|c|c|c|c|c|c|c|c|c|}
\hline \multicolumn{2}{|c|}{ Variable and Mean } & \multirow{2}{*}{$\begin{array}{c}\begin{array}{c}\text { Standard } \\
\text { Deviation }\end{array} \\
0.540\end{array}$} & \multirow[t]{2}{*}{1} & \multirow[t]{2}{*}{2} & \multirow[t]{2}{*}{3} & \multirow[t]{2}{*}{4} & \multirow[t]{2}{*}{5} & \multirow[t]{2}{*}{6} & \multirow[t]{2}{*}{7} \\
\hline $\begin{array}{c}1 \text { Past } \\
\text { negative }\end{array}$ & 2.666 & & & & & & & & \\
\hline $\begin{array}{l}2 \text { Present } \\
\text { hedonistic }\end{array}$ & 3.164 & 0.506 & $0.281^{* *}$ & & & & & & \\
\hline 3 Future & 3.661 & 0.463 & $-0.092 *$ & -0.081 & & & & & \\
\hline $\begin{array}{c}4 \text { Past } \\
\text { positive }\end{array}$ & 3.288 & 0.530 & $0.427^{* *}$ & $0.357^{* *}$ & $0.184^{* *}$ & & & & \\
\hline $\begin{array}{l}5 \text { Present } \\
\text { fatalistic }\end{array}$ & 2.686 & 0.568 & $0.452 * *$ & $0.447^{* *}$ & $-0.297^{* *}$ & $0.235^{* *}$ & & & \\
\hline $\begin{array}{l}6 \text { Emotional } \\
\text { exhaustion }\end{array}$ & 2.472 & 1.412 & $0.379 * *$ & $0.208 * *$ & $-0.173^{* *}$ & $0.235^{* *}$ & $0.236^{* *}$ & & \\
\hline 7 Cynicism & 2.523 & 1.229 & 0.336 ** & $0.196^{* *}$ & $-0.188^{* *}$ & $0.121 * *$ & $0.218^{* *}$ & $0.631^{* *}$ & \\
\hline $\begin{array}{l}8 \text { Professional } \\
\text { Efficacy }\end{array}$ & 4.378 & 1.050 & $-0.086^{*}$ & 0.068 & $0.404^{* *}$ & $0.142 * *$ & -0.047 & $-0.089 *$ & $-0.141^{* *}$ \\
\hline
\end{tabular}

Note: ${ }^{* *}$. The correlation is significant for 0.01 (bilateral). *. The correlation is significant for 0.05 (bilateral).

After calculating the descriptive values, whether there were significant differences when comparing workers in the naval sector with workers in other sectors was determined. For this, the MANOVA test was applied, the result of which is shown in Table 2. 
Table 2. MANOVA of the variables depending on the professional sector (naval vs. other sectors).

\begin{tabular}{|c|c|c|c|c|c|}
\hline & & Sum of Squares Type III & Mean Square & $\mathbf{F}$ & Sig. \\
\hline \multirow{8}{*}{ Corrected model } & $\begin{array}{c}1 \text { Past } \\
\text { negative }\end{array}$ & $1.232^{\mathrm{a}}$ & 1.232 & 4.489 & 0.035 \\
\hline & $\begin{array}{l}2 \text { Present } \\
\text { hedonistic }\end{array}$ & $0.034^{b}$ & 0.034 & 0.131 & 0.717 \\
\hline & 3 Future & $1.221^{\mathrm{c}}$ & 1.221 & 5.553 & 0.019 \\
\hline & $\begin{array}{c}4 \text { Past } \\
\text { positive }\end{array}$ & $0.922^{d}$ & 0.922 & 3.249 & 0.072 \\
\hline & $\begin{array}{l}5 \text { Present } \\
\text { fatalistic }\end{array}$ & $0.947^{\mathrm{e}}$ & 0.947 & 2.885 & 0.090 \\
\hline & $\begin{array}{l}6 \text { Emotional } \\
\text { exhaustion }\end{array}$ & $22.561^{f}$ & 22.561 & 12.023 & 0.001 \\
\hline & 7 Cynicism & $0.978^{g}$ & 0.978 & 0.669 & 0.414 \\
\hline & $\begin{array}{l}8 \text { Professional } \\
\text { Efficacy }\end{array}$ & $21.575^{h}$ & 21.575 & 21.462 & 0.000 \\
\hline
\end{tabular}

Note: Sig.: signification. ${ }^{\mathrm{a}} \cdot \mathrm{R}^{2}=0.010 ;{ }^{\mathrm{b}} \cdot \mathrm{R}^{2}=0.000 ;{ }^{\mathrm{c}} \cdot \mathrm{R}^{2}=0.012{ }^{\mathrm{d}} \cdot \mathrm{R}^{2}=0.007 ;{ }^{\mathrm{e}} \cdot \mathrm{R}^{2}=0.006{ }^{\mathrm{f}} \cdot \mathrm{R}^{2}=0.026 ;^{\mathrm{g}} \cdot \mathrm{R}^{2}=0.002{ }^{\mathrm{h}} \cdot \mathrm{R}^{2}=0.046$.

The MANOVA, used to determine if there are differences between the three personality factors and being burnt-out among the naval workers and those of the control group, obtained the following results:

Concerning the personality variables, significant differences were found in four of the five variables: negative past, future, positive past and fatalistic present. No significant differences were found in the present hedonistic. Regarding the negative past, the group of employees in the naval sector obtained an average of 2.611, compared to the score of 2.770, which means employees in the naval sector scored significantly less in the negative past $(p \leq 0.01)$. Regarding the future, the average of subjects in the naval sector was 0.623 , compared to 3.732 employees in other sectors, which means the perception of the future is significantly more positive in employees who are not in the naval sector $(p=0.006)$. With respect to the positive past, workers in the naval sector obtained an average score of 3.238, compared to 3.394 for workers in other sectors; that is, workers in other sectors thought that their past had been more positive, and the differences were significant $(p \leq 0.00)$. Regarding the fatalistic present, naval workers obtained an average score of 2.651, compared to 2.753 for workers in other sectors; therefore, it can be said that workers from the naval sector are more pessimistic about their future than workers from other sectors $(p=0.039)$.

Regarding being burnt-out, two of the variables were significant: emotional exhaustion $(p \leq 0.00)$ and professional efficacy $(p=0.000)$. Regarding emotional exhaustion, the workers in the naval sector obtained an average score of 0.292 , compared to a score of 2.806 for the workers in the control group; that is, there is a greater emotional burnout in professionals from other sectors. With regard to professional efficiency, workers score, on average, 4.207 , compared to a score of 4.703 for workers in other sectors; that is, employees in other sectors feel more professionally effective.

The results of the MANOVA can be consulted in Table 2.

The data were also subjected to a binary logistic regression, taking as a criterion variable the sector of professional activity and as an independent criterion all the factors of the personality test (5) and of burnout (3). The $-2 \log$ plausibility value was 531.570 . Cox and Snell's $\mathrm{R}^{2}$ was 0.099 , and Nagelkerke's $\mathrm{R}^{2}$ was 0.137 . The Classification Table obtains an overall percentage of correct classifications of $69.1 \%$; that is, in the case of $20 \%$, the level of random classifications is exceeded.

Table 3 shows the results of the variables that have been introduced into the equation, with emotional exhaustion and professional efficacy being the clearly predictive variables; that is, the psychological difference between workers in the naval sector and those in other 
sectors is better predicted based on these two variables. The sign is positive in these two variables; that is, both variables are more positive in workers in the naval sector. These data coincide with those of the analysis of the MANOVA.

Table 3. Logistic regression binary, variables in the equation comparing shipyard naval workers vs. control group.

\begin{tabular}{ccccccc}
\hline Variables & B & E.T. & Wald & d.f. & Sig. & Exp (B) \\
\hline Past negative & 0.270 & 0.254 & 1.132 & 1 & 0.287 & 1.310 \\
Present hedonistic & -0.314 & 0.240 & 1.711 & 1 & 0.191 & 0.730 \\
Future & 0.314 & 0.281 & 1.254 & 1 & 0.263 & 1.369 \\
Past positive & -0.010 & 0.233 & 0.002 & 1 & 0.964 & 0.990 \\
Present fatalistic & 0.303 & 0.236 & 1.649 & 1 & 0.199 & 1.354 \\
Emotional exhaustion & 0.372 & 0.105 & 12.465 & 1 & 0.000 & 1.450 \\
Cynicism & -0.150 & 0.117 & 1.642 & 1 & 0.200 & 0.861 \\
Professional Efficacy & 0.520 & 0.126 & 17.124 & 1 & 0.000 & 1.682 \\
Constant & -5.164 & 1.335 & 14.973 & 1 & 0.000 & 0.006 \\
\hline
\end{tabular}

Note: B, coefficient B for the constant (also called the intercept) in the null model; E.T., standard error around the coefficient for the constant; Wald, Wald chi-square test that tests the null hypothesis that the constant equals 0 ; d.f., degrees of freedom for the Wald chi-square test; Sig., significance; Exp (B), exponentiation of the B coefficient, which is an odds ratio.

\section{Discussion}

The purpose of the research was to analyze the relationship between the time perspective of Spanish shipyard workers in relation to burnout compared to other blue-collar workers in other sectors, as no study to date has examined this issue for blue-collar Spanish workers. Our study indicates that shipyard staff in northern Spain have an elevated risk of becoming burnt-out (emotional exhaustion, personal efficacy and cynicism) and of reporting a negative past and negative future time perspective.

The Hypothesis 1-3 have been accepted or rejected on the basis of these results,

Workers in the naval sector will obtain higher scores in the temporal dimension of personality (Zimbardo model) of the negative past, negative present and negative future time perspective than workers in other sectors. (H1)

On the basis of this study, we can accept this hypothesis. Workers in the naval sector score higher on the negative past and negative fatalistic present and future perspective, which is negative compared to workers in other sectors.

Workers in the naval sector will obtain lower scores in the temporal dimension of personality (Zimbardo model) of the hedonistic present, future and positive past than workers in other labor sectors. (H2)

This hypothesis can only be partially accepted. No significant differences between the two groups have been found for the hedonistic present. In the variables future and positive past, significant differences between both groups have been found. Workers in the naval sector have a less positive present and positive past than workers in the comparison group.

Workers in the naval sector will obtain higher scores on the burnout scales (emotional exhaustion) and cynicism when compared with the sample of workers from other sectors and are lower in professional efficiency. (H3)

The third hypothesis can only be partially accepted. Workers in the naval sector score higher in emotional exhaustion and lower in professional efficiency. No differences between both groups have been found in the variable cynicism.

Earlier studies on time perspective have found an association between a past negative time perspective and developing neuroticism and a negative mood [44,45]. A systematic review by Kooij found that workers with a lower socioeconomic status (SES) have a significant association with a negative future time perspective, defined by having a lower income and a more practical type of education [46]. This reflects how workers with a lower 
economic status are more prone to developing a negative future time perspective compared with workers in a middle or high economic class. The evidence, though, is scarce in the literature. The current study shows that there are different working conditions by field of work with, predominantly, concern practical workers. Workers in the naval sector score higher on a negative present and future time perspective compared to other blue-collar workers or workers with a lower socioeconomic status. Different personal and contextual factors probably play a role in the different blue-collar fields.

Furthermore, earlier research has revealed some evidence for the association between future time perspective, locus of control and self-efficacy [46]. This is relevant as low self-efficacy has been related to a higher risk of developing burnout $[47,48]$. In relation to employability and participation in sports, as well as educational settings [48]. The relationship between self-efficacy and the prevention of disability has not been defined in the literature on occupational health prevention yet.

\section{Limitations}

The present study holds several limitations that might impede the ability to generalize the results. Firstly, we do not know if the associations between a positive time perspective and burnout are different for white-collar workers than blue-collar workers in similar domains or even different countries. There is probably no difference, as earlier research in Finland has found that job stressors are the same for blue-collar workers as white-collar workers [49]. The intensity of the stressors and resources to compensate for the stressors will probably be different between blue-collar workers and white-collar workers.

A second limitation of this study may be that the results rest on cross-sectional data and not observational or longitudinal data. More research is needed to strengthen the results that this study has found.

A third limitation of this research that needs more investigation is to explain why naval workers experience a more negative time perspective than workers in other practicalbased fields. A combination of environmental but also social factors potentially plays a role to verify this difference. Successive generations work at the shipyard in the north of Spain. This may explain the difference in the time perspective view between both groups of workers.

However, this study provides new insights into the possible factors that can influence exhaustion and burnout among shipyard workers in comparison to other blue-collar workers. Environmental factors such as working conditions and social support at work may play an essential role in preventing the development of burnout. On the basis of this study, it is essential to train supervisors and staff of occupational health services at the shipyard to detect signs and symptoms of negative time perspective and a lack of self-efficacy in order to prevent mental problems at the workplace. Furthermore, it is necessary to investigate further which working factors contribute to a negative past and negative future time perspective within the shipyard. Other studies have shown that a lack of autonomy and high demands have contributed to high levels of stress and a lack of job satisfaction in shipyard workers [26-50]. The harsh environmental working conditions at the shipyard due to noise and air pollution [31] have a negative effect on the mental and physical health of blue-collar shipyard workers [50]. Other studies have found an association between physical work demands, a shortened expected working life [51], as well as men being more exposed to more physically demanding work and less support at work than women [52].

Future studies should pay more attention to personal and environmental conditions when developing suitable Human Resource instruments, work disability prevention programs, as well as successful aging at work practices [53]. The immediate implementation of these interventions is needed for the activation of protective factors that can reduce and avoid the development of severe psychological outcomes and burnout [54].

In addition, there is the need for organizational involvement on the basis of participatory interventions that include blue-collar employees in the process of action taken at 
the workplace in order to improve healthy working conditions and life-long employability, as well as paying more attention to the individual employee at work. More awareness is needed about preventive measures in order to avoid mental problems due to a negative time perspective.

\section{Conclusions}

This study indicates that shipyard staff in northern Spain have an elevated risk of becoming burnt-out compared to workers in other sectors due to a negative past, present and negative future time perspective. This might be a consequence of constant understimulation and monotonous and repetitive work. Furthermore, working at shipyards and the working conditions within shipyards are harsh. This predominantly blue-collar work is related to heavy manual and repetitive work. Shipyard workers are frequently exposed to ventilation and machinery noise. Furthermore, the working conditions are difficult because of the high temperatures and air pollution due to the use of chemicals at the shipyard.

Author Contributions: Conceptualization, S.D., A.R.-B. and M.C.; methodology, S.D., A.R.-B. and M.C.; validation, S.D., A.R.-B. and M.C.; formal analysis, M.C.; data curation, M.C.; writing—original draft preparation, A.R.-B., M.C. and S.D.; writing-review and editing, A.R.-B., S.D., M.C., A.d.L. and J.L.-G. All authors have read and agreed to the published version of the manuscript.

Funding: This research received no external funding.

Data Availability Statement: The data presented in this study are available on request from the corresponding author.

Conflicts of Interest: The authors declare no conflict of interest.

\section{References}

1. Zimbardo, P.G.; Boyd, J.N. Putting time in perspective: A valid reliable individual differences metric. J. Personal. Soc. Psychol. 1999, 77, 1271-1288. [CrossRef]

2. Zimbardo, P.G.; Boyd, J.N. The time Paradox: The New Psychology of Time that will Change Your Life; The Free Press: New York, NY, USA, 2008.

3. Lima da Silva, J.L.; Da Silva Soares, R.; Rangel Teixeira, E.; Vago Daher, D.; De Almeida, J.A.; Anjos de Almeida, J.H. Degree of stress among shipyard workers: Cross-sectional study. Online Braz. J. Nurs. 2016, 15, 61-72. [CrossRef]

4. Sobol-Kwapinska, M.; Jankowski, T. Positive Time: Balanced time perspective and positive orientation. J. Happiness Stud. 2016, 17, 1511-1528. [CrossRef]

5. Schaufeli, W.; Salanova, M. Burnout, Boredom and Engagement at the Workplace; An Introduction to Contemporary Work, Psychology; Coord, C.W.M., de Jonge, J., Taris, T.W., Eds.; John Wiley \& Sons, Ltd.: London, UK, 2014.

6. Swider, B.W.; Zimmerman, R.D. Born to burnout: A meta-analytic path model of personality, job burnout, and work outcomes. J. Vocat. Behav. 2010, 76, 487-506. [CrossRef]

7. Loukidou, L.; Loan-Clarke, J.; Daniels, K. Boredom in the workplace: More than monotonous tasks. Int. J. Manag. Rev. 2009, 11, 381-405. [CrossRef]

8. Van der Heijden, G.; Schepers, J.; Nijssen, E. Understanding workplace boredom among white collar employees: Temporal reactions and individual differences. Eur. J. Work Organ. Psychol. 2012, 21, 349-375. [CrossRef]

9. Maslach, C.; Jackson, S.E. The measurement of experienced burnout. J. Organ. Behav. 1981, 2, 99-113. [CrossRef]

10. Bakker, A.B.; Oerlemans, W.G. Momentary Work happiness as a function of enduring burnout and work engagement. J. Psychol. 2016, 150, 755-778. [CrossRef]

11. Busis, N.A.; Shanafelt, T.D.; Keran, C.M.; Levin, K.H.; Schwarz, H.B.; Molano, J.R.; Vidic, T.R.; Kass, J.S.; Miyasaki, J.M.; Sloan, J.A.; et al. Burnout, career satisfaction, and well-being among US neurologists in 2016. Neurology 2017, 88, 797-808. [CrossRef]

12. Peng, J.; Li, D.; Zhang, Z.; Tian, Y.; Miao, D.; Xiao, W.; Jiaxi, Z. How can core self-evaluations influence job burnout? The key roles of organizational commitment and job satisfaction. J. Health Psychol. 2016, 21, 50-59. [CrossRef]

13. Chacón-Cuberos, R.; Martínez-Martínez, A.; García-Garnica, M.; Pistón-Rodríguez, M.D.; Expósito-López, J. The Relationship between Emotional Regulation and School Burnout: Structural Equation Model According to Dedication to Tutoring. Int. J. Environ. Res. Public Health 2019, 16, 4703. [CrossRef]

14. Gong, Z.; Chen, Y.; Wang, Y. The influence of emotional intelligence on job burnout and job performance: Mediating effect of psychological capital. Front. Psychol. 2019, 10, 1-11. [CrossRef]

15. Maslach, C.; Schaufeli, W.B.; Leiter, M.P. Job burnout. Annu. Rev. Psychol. 2001, 52, 397-422. [CrossRef] [PubMed] 
16. Maslach, C.; Leiter, M.P. Understanding the burnout experience: Recent research and its implications for Psychiatry. World Psychiatry 2016, 15, 103-111. [CrossRef]

17. Inoue, M. Cross-Sectional study on Occupational noise and hypertension in the workplace. Arch. Environ. Occup. Health 2005, 60, 106-110. [CrossRef] [PubMed]

18. Golonka, K.; Gawlowska, M.; Mojsa-Kaja, J.; Marek, T. Psychophysiological characteristics of burnout syndrome: Resting-state EEG analysis. Biomed Res. Int. 2019, 3764354. [CrossRef] [PubMed]

19. Melo, L.; Carlotto, M.S. Prevalence and predictors of burnout among firefighters. Psicol. Ciencia.E Profissao. 2016, 36, 668-681. [CrossRef]

20. Morales-Rodríguez, F.M.; Pérez-Mármol, J.M.; Brown, T. Education Burnout and Engagement in occupational therapy undergraduate students and its associated factors. Front. Psychol. 2019, 10, 2889. [CrossRef] [PubMed]

21. Grover, S.; Sahoo, S.; Bhalla, A.; Avasthi, A. Psychological problems and burnout among medical professionals of a tertiary care hospital of North India: A cross-sectional study. Indian J. Psychiatry 2018, 60, 175-188. [CrossRef]

22. Salvagioni, D.A.J.; Melanda, F.N.; Mesas, A.E.; González, A.D.; Gabani, F.L.; de Andrade, S.M. Physical, psychological and occupational consequences of job burnout: A systematic review of prospective studies. PLoS ONE 2017, 12, e0185781. [CrossRef]

23. Kim, Y.; Lee, E.; Lee, H. Association between workplace bullying and burnout, professional quality of life, and turnover intention among clinical nurses. PLoS ONE 2019, 14, 1-13. [CrossRef]

24. Sharma, R.; Sharma, N.P. Opening the gender diversity black box: Causality of perceived gender equity and locus of control and mediation of work engagement in employee well-being. Front. Psychol. 2015, 6, 1371. [CrossRef] [PubMed]

25. International classification of diseases 11th Revision. In The global Standard for Diagnostic Health Information (CIE-11); World Health Organization: Geneva, Switzerland, 2018.

26. Alhaffar, B.A.; Abbas, G.; Alhaffar, A.A. The prevalence of burnout syndrome among resident physicians in Syria. J. Occup. Med. Toxicol. 2019, 14, 1-8. [CrossRef] [PubMed]

27. Wiesmann, U.; Ballas, J.; Hannich, H.J. Sense of coherence, time perspective and positive aging. J. Happiness Stud. 2018, 19, 817-839. [CrossRef]

28. Loose, T.; Robiou du Pont, L.; Acier, D.; El-Baalbaki, G. Time perspectives mediate the relationship between Personality traits and alcohol consumption. Time Soc. 2019, 28, 1148-1166. [CrossRef]

29. Sobol-Kwapinska, M.; Jankowski, T.; Przepiorka, A.; Oinyshi, I.; Sorokowski, P.; Zimbardo, P. What is the structure of time? A study on time perspective in the United States, Poland, and Nigeria. Front. Psychol. 2018, 9, 2078. [CrossRef] [PubMed]

30. Witowska, J.; Zajenkowski, M. How is perception of time associated with cognitive functioning? The relationship between time perspective and executive control. Time Soc. 2019, 28, 1148-1166. [CrossRef]

31. Rönnlund, M.; del Missier, F.; Mäntylä, T.; Carelli, M.G. The fatalistic decision maker: Time perspective, working memory, and older adults' decision-making competence. Front. Psychol. 2019, 10, 2038. [CrossRef]

32. Kocayoruk, E.; Simsek, O.F. The validity and reliability of the Turkish brief version of the Zimbardo Time Perspective Inventory for adolescents. Dusunen Adam J. Psychiatry Neurol. Sci. 2020, 1, 40-49. [CrossRef]

33. Nowack, K. Unfinished sympathies: Influence of individual temporal orientation on music preferences. Psychol. Music 2019, 47, 736-746. [CrossRef]

34. Zimbardo, P.; Keough, K.; Boyd, J.N. Present time perspective as a predictor of risky driving. Personal. Individ. Differ. 1997, 23, 1007-1023. [CrossRef]

35. Kairys, A.; Miliauskaite, A. Time perspective and personality. In Time Perspective Theory: Review, Research and Application; Stolarski, M., Fieulaine, N., van Beek, W., Eds.; Springer: Cham, Switzerland, 2015; pp. 99-113.

36. Codina, N.; Pestana, J.V. Time matters differently in leisure experience for men and women: Leisure dedication and time perspective. Int. J. Environ. Res. Public Health 2019, 16, 2513. [CrossRef] [PubMed]

37. Cernas-Ortiz, D.A.; Mercado-Salgado, P.; Davis, M.A. Perspectiva futura de tiempo, satisfacción laboral y compromiso organizacional: El efecto mediador de la autoeficacia, la esperanza y la vitalidad [Future time perspective, job satisfaction, and organizational commitment: The mediating effect of self-efficacy, hope, and vitality]. J. Work Organ. Psychol. 2018, 34, 1-9. [CrossRef]

38. Mohammed, S.; Marhefka, J.T. How have we, do we, and will we measure time pespective? A review of methodological and measurement issues. J. Organ. Behav. 2020, 41, 276-293. [CrossRef]

39. Rudolph, C.W.; Kooij, D.T.A.M.; Rauvola, R.S.; Zacher, H. Occupational future time perspective: A meta-analysis of antecedents and outcomes. J. Organ. Behav. 2018, 39, 229-248. [CrossRef]

40. Cernas-Ortiz, D.A.; Davis, M.A. Future and past negative time perspective influences on job satisfaction and organizational commitment in Mexico and the United States. Manag. Res. J. Iberoam. Acad. Manag. 2016, 14, 317-338. [CrossRef]

41. Navarro, J.; Roe, R.A.; Artiles, M.I. Taking time seriously: Changing practices and perspectives in work /organizational psychology. J. Work Organ. Psychol. 2015, 31, 135-145. [CrossRef]

42. Díaz-Morales, J.F. Estructura factorial y fiabilidad del Inventario de Perspectiva Temporal de Zimbardo [Factor structure and reliability of Zimbardo's Time Perspective Inventory]. Psicothema 2006, 18, 565-571.

43. Schaufeli, W.B.; Leiter, M.P.; Maslach, C.; Jackson, S.E. The MBI-General Survey. In Maslach Burnout Inventory Manual, 3rd ed.; Maslach, C., Jackson, S.E., Leiter, M.P., Eds.; Consulting Psychologists Press: Palo Alto, CA, USA, 1996. 
44. Van Beek, W.; Berghuis, H.; Kerkhof, A.; Beekman, A. Time perspective, personality and psychopathology: Zimbardo's Time Perspective Inventory in psychiatry. Time Soc. 2010, 20, 364-374. [CrossRef]

45. Schaufeli, W.B.; Leiter, M.P.; Maslach, C.; Jackson, S.E. Maslach Burnout Inventory-General Survey. In The Maslach Burnout Inventory-Test Manual, 3rd ed.; Maslach, C., Jackson, S.E., Leiter, M.P., Eds.; Consulting Psychologists Press: Palo Alto, CA, USA, 1996.

46. Kooij, D.T.A.M.; Kanfer, R.; Betts, M.; Rudolph, C.W. Future time perspective: A systematic review and meta-analysis. J. Appl. Psychol. 2018, 103, 867-893. [CrossRef]

47. Partelow, S.; Seara, T.; Pollnac, R.B.; Ruiz, V. Job satisfaction in small-scale fisheries: Comparing differences between Costa Rica, Puerto Rico and the Dominican Republic. Mar. Policy 2020, 117, 103949. [CrossRef]

48. Schwarzer, R.; Hallum, S. Perceived teacher self-efficacy as a predictor of job stress and burnout: Mediation analyses. Appl. Psychol. 2008, 57, 152-171. [CrossRef]

49. Toppinen-Tanner, S.; Kalimo, R.; Mutanen, P. The process of burnout in white-collar and blue-collar jobs: Eight-year prospective study of exhaustion. J. Organ. Behav. 2002, 23, 555-570. [CrossRef]

50. Padula, R.S.; Chiavegato, L.D.; Cabral, C.M.; Almeid, T.; Ortiz, T.; Carregaro, R.L. Is occupational stress associated with work engagement? Work 2012, 41, 2963-2965. [CrossRef]

51. Pedersen, J.; Schultz, B.B.; Madsen, I.E.H.; Solovieva, S.; Andersen, L.L. High physical work demands and working life expectancy in Denmark. Occup. Environ. Med. 2020, 77, 1-7. [CrossRef]

52. Reid, A.; Daly, A.; LaMontagne, A.D.; Milner, A.; Ronda Pérez, E. Descriptive study of workplace demand, control and bullying among migrant and Australian-born workers by gender: Does workplace support make a difference? BMJ Open 2020, 10, e033652. [CrossRef] [PubMed]

53. Dorien-Kooij, T.A.M.; Zacher, H.; Wang, M.; Heckhausen, J. Successful aging at work: A process model to guide future research and practice. Ind. Organ. Psychol. 2020, 1-21. [CrossRef]

54. Vagni, M.; Giostra, V.; Maiorano, T.; Santaniello, G.; Pajardi, D. Pesonal accomplishment and hardiness in reducing emergency stress and burnout among Covid-19 emergency workers. Sustainability 2020, 12, 9071. [CrossRef] 